\title{
Crescimento, produtividade e bienalidade do cafeeiro em função do espaçamento de cultivo
}

\author{
Sérgio Parreiras Pereira(1), Gabriel Ferreira Bartholo(2), Danielle Pereira Baliza ${ }^{(3)}$, Fabricio Moreira Sobreira(4) \\ e Rubens José Guimarães ${ }^{(3)}$
}

\begin{abstract}
(1)Instituto Agronômico de Campinas, Avenida Barão de Itapura, o 1.481, CEP 13012-970 Campinas, SP. E-mail: pereiracafes@yahoo.com.br (2)Embrapa Cerrados, BR 020, Km 18, Caixa Postal 08223, CEP 73310-970 Planaltina, DF. E-mail: gbartholo@gmail.com (3)Universidade Federal de Lavras, Departamento de Agricultura, Caixa Postal 3037, CEP 37200-000 Lavras, MG. E-mail: danibaliza@yahoo.com.br, rubensjg@dag.ufla.br (4)Universidade Federal de Viçosa, Departamento de Fitotecnia, Caixa Postal 231, CEP 36570-000 Viçosa, MG. E-mail: sobreirafm@bol.com.br
\end{abstract}

Resumo - O objetivo deste trabalho foi avaliar as consequências da redução no espaçamento entre linhas e entre plantas na linha de plantio sobre o crescimento, a produtividade e a bienalidade de produção do cafeeiro (Coffea arabica). Utilizou-se o delineamento experimental de blocos ao acaso, com três repetições, em esquema fatorial $4 \times 3$. Foram utilizadas quatro distâncias entre as linhas $(2,0,2,5$ 3,0 e 3,5 m) e três distâncias entre as plantas na linha de plantio $(0,50,0,75$ e $1,00 \mathrm{~m})$, o que totalizou 12 tratamentos. A produtividade e a produção por planta foram avaliadas anualmente entre 1994 e 2001, e o crescimento foi avaliado em 2002. A redução no espaçamento entre as linhas e entre as plantas na linha de plantio aumenta a produtividade da lavoura cafeeira. Os espaçamentos entre as linhas e entre as plantas influenciam o crescimento e a arquitetura dos cafeeiros.

Termos para indexação: Coffea arabica, adensamento, manejo, fenologia.

\section{Growth, productivity and bienniality of coffee plants according to cultivation spacing}

\begin{abstract}
The objective of this work was to evaluate the consequences of spacing reduction between rows and between plants in the planting row on growth, productivity and bienniality of coffee plants (Coffea arábica). The experimental design was a randomized complete block, with three replicates, in a $4 \times 3$ factorial arrangement. Four distances between rows $(2.0,2.5,3.0$ and $3.5 \mathrm{~m})$ and three distances between plants in the planting rows $(0.50,0.75$ and $1.00 \mathrm{~m})$ were used, which totalized 12 treatments. The productivity and the production per plant were assessed annually between 1994 and 2001, and the growth was evaluated in 2002. The reduction of spacing between rows and between plants in the planting row increases the productivity of coffee plants. The spacing between the rows and plants influences the growth and architecture of the coffee plant.
\end{abstract}

Index terms: Coffea arabica, density, management, phenology.

\section{Introdução}

Atualmente, parece haver uma tendência de redução do espaçamento de plantio da maioria das culturas, sejam elas perenes (Xue \& Hagihara, 2008; Souza et al., 2009a) ou anuais (Demetrio et al., 2008; Bruin \& Pedersen, 2009; Souza et al., 2009b; Kouassi \& $\mathrm{Bi}, 2010)$. Na cafeicultura de montanha e mesmo nas áreas menos declivosas com colheita mecanizada (Paulo et al., 2005; Oliveira et al., 2007), a variação no espaçamento de plantio entre as linhas e entre as plantas na linha provoca consideráveis impactos econômicos, não apenas pela influência na produtividade, mas também pela alteração no manejo da lavoura.
Ganhos na produtividade têm sido relatados com o adensamento do cultivo do cafeeiro (Toledo \& Barros, 1999; Braccini et al., 2002, 2005; Paulo et al., 2005; Augusto et al., 2006; Carvalho et al., 2006b; Bragança et al., 2009); contudo, com o crescimento da lavoura, há redução na produtividade ao longo dos anos, em virtude da competição entre as plantas (Pavan et al., 1994; Toledo \& Barros, 1999; Braccini et al., 2002, 2005; Paulo et al., 2005; Carvalho et al., 2006b). Por isso, tornou-se necessário adotar operações de manejo para maximizar a produtividade e a viabilidade econômica desses cultivos (Toledo \& Barros, 1999; Pereira et al., 2007; Youkhana \& Idol, 2009). 
Na literatura, a maioria dos trabalhos relata variações na produtividade de culturas de acordo com diferentes densidades de plantio, mas sem apresentar discussões isoladas sobre os efeitos dos espaçamentos na linha e entre as linhas (Braccini et al., 2005; Paulo et al., 2005; Augusto et al., 2006; Martinez et al., 2007). Para um manejo eficaz, é preciso considerar, além da produtividade, a influência dos espaçamentos sobre a bienalidade e o crescimento do cafeeiro, que está limitada a poucos trabalhos com enfoque na densidade de cultivo. Alguns autores recomendam estudos mais abrangentes a respeito do tema (Hernandez-Martinez et al., 2009), em decorrência da pouca discussão sobre o manejo de cafezais em diferentes espaçamentos de cultivo.

O objetivo deste trabalho foi avaliar as consequências da redução no espaçamento entre as linhas e entre as plantas na linha sobre o crescimento, a produtividade e a bienalidade do cafeeiro.

\section{Material e Métodos}

$\mathrm{O}$ experimento foi conduzido na fazenda experimental da Empresa de Pesquisa Agropecuária de Minas Gerais, em Machado, MG $\left(21^{\circ} 40^{\prime} \mathrm{S}, 45^{\circ} 55^{\prime} \mathrm{W}\right.$, a $881 \mathrm{~m}$ de altitude), de janeiro de 1992 a agosto de 2002 . A precipitação anual e a temperatura média anual, para esse período, foram de $1.583,7 \mathrm{~mm}$ e $21,03^{\circ} \mathrm{C}$, respectivamente (Figura 1).

Utilizou-se o delineamento experimental em blocos ao acaso, com três repetições, em esquema fatorial $4 \times 3$, com quatro distâncias entre as linhas $(2,0,2,5$, $3,0$ e $3,5 \mathrm{~m})$ e três distâncias entre as plantas na linha de plantio $(0,5,0,75$, e $1,0 \mathrm{~m})$, o que totalizou 12 tratamentos. As parcelas foram compostas de três linhas de plantio, com $12 \mathrm{~m}$ de comprimento, e a linha central foi considerada como parcela útil. Já que o espaçamento na linha de plantio variou, o número de plantas no comprimento de $12 \mathrm{~m}$ foi diferente: $72,48 \mathrm{e}$ 36 plantas por parcela, respectivamente.

O plantio foi realizado em janeiro de 1992, com uma planta por cova de café arábica (Coffea arabica L.) cultivar Catuaí Vermelho IAC - H2077-2-544. Foram feitas adubações com corretivos e nutrientes (Guimarães et al., 1999). O ensaio foi instalado em uma área de relevo plano a suave ondulado, originalmente sob vegetação de Cerrado, em um Latossolo Vermelho de textura argilosa. Os resultados da análise química e granulométrica do solo, na camada $0-20 \mathrm{~cm}$ de profundidade, antes da implantação do experimento, indicaram: $\mathrm{pH}$ em água de 4,0; $18 \mathrm{~g} \mathrm{~kg}^{-1}$ de carbono orgânico; $1,0 \mathrm{e} 11 \mathrm{mg} \mathrm{dm}^{-3}$ de $\mathrm{P}$ e $\mathrm{K}^{+}$(Mehlich 1), respectivamente; 0,2, 0,1 e 0,5 $\mathrm{cmol}_{\mathrm{c}} \mathrm{dm}^{-3}$ de $\mathrm{Ca}^{2+}, \mathrm{Mg}^{2+}$ e $\mathrm{Al}^{3+}$ (extrator $\mathrm{KCl} 1 \mathrm{~mol}$ $\left.\mathrm{L}^{-1}\right)$, respectivamente; 484, 46 e $470 \mathrm{~g} \mathrm{~kg}^{-1}$ de areia, silte e argila, respectivamente.

No plantio, antes da aração da área, foram aplicadas 4,0 $\mathrm{Mg} \mathrm{ha}{ }^{-1}$ de calcário incorporado à profundidade de $20 \mathrm{~cm}$ por meio de gradagem. Sulcou-se o terreno de acordo com os espaçamentos estabelecidos. A adubação de plantio constou de $300 \mathrm{~g}$ de superfosfato simples por metro linear de sulco. No ano do plantio, a dose total de adubo aplicada em cobertura foi dividida em dois parcelamentos (fevereiro e abril). A partir do primeiro ano pós-plantio, as adubações foram feitas em quatro parcelamentos (outubro, dezembro, janeiro e março), ao distribuir-se o adubo sob a copa das plantas. Os micronutrientes cobre, boro e zinco foram aplicados em quatro pulverizações anuais em agosto, novembro, fevereiro e março, de acordo com a análise foliar. A calagem foi realizada a cada quatro anos conforme a análise de solo, mas não foi realizada a gessagem em nenhum dos anos. As adubações com NPK foram feitas conforme a carga pendente, tendo como referência Lopes \& Guimarães et al. (1989).

Todos os tratamentos foram avaliados anualmente entre 1994 e 2002, para determinação da produtividade

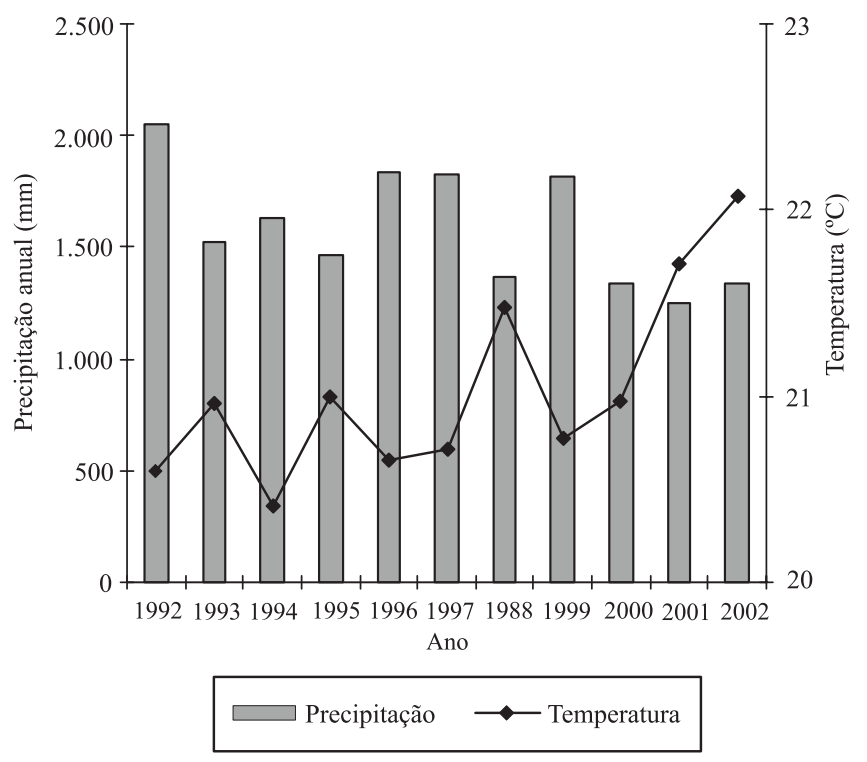

Figura 1. Temperatura média anual e precipitação pluvial anual no período de 1992 a 2002. Fonte: Estação Climatológica de Machado, Instituto Nacional de Meteorologia. 
e da produção por planta. As colheitas foram realizadas no momento em que as parcelas apresentavam menos de $20 \%$ de frutos verdes. Foi determinado o peso dos frutos, na forma de "café da roça", por unidade experimental e por planta. O café da roça é o café colhido com diversos estádios de maturação misturados: verde, cereja, passa e seco. Do total, retirou-se uma amostra de $2 \mathrm{~kg}$, que foi seca até $11 \%$ de umidade, beneficiada e pesada. Os dados obtidos foram transformados em sacas de café beneficiado por hectare e em gramas de café beneficiado por planta, segundo proposto por Mendes et al. (1994).

A produção de café por biênio foi obtida do somatório da produção a cada dois anos. A bienalidade da cultura, tanto em produtividade (sacas beneficiadas por hectare), quanto em produção individual (gramas de café beneficiado por planta), foi medida matematicamente, conforme Stevens (1949). De acordo com o autor, a magnitude da bienalidade pode ser medida ao subtrairse a média da produção dos anos de baixa produção da média dos anos de alta; sempre com o uso de um número par de anos. Foram utilizados os dados referentes aos anos entre 1995 e 2002. Subtraiu-se da média dos anos de alta produção (1996, 1998, 2000 e 2002) a média dos anos de baixa produção (1995, 1997, 1999 e 2001).

Os dados de crescimento da cultura foram coletados em agosto de 2002, logo após a colheita. Foram avaliados: a altura das plantas, obtida com régua graduada em centímetros, na posição paralela ao ramo ortotrópico; o diâmetro da copa, medido com régua graduada em centímetros, na altura de $1,50 \mathrm{~m}$ do solo, no sentido transversal à linha de plantio, e o comprimento dos ramos plagiotrópicos de um lado ao outro do cafeeiro; a altura dos ramos plagiotrópicos inferiores, medida com régua graduada em centímetros, na posição vertical entre o solo e a inserção dos primeiros ramos; o diâmetro do caule, obtido com paquímetro a $5 \mathrm{~cm}$ de altura do solo, no sentido da maior e da menor largura; obteve-se a média desses valores.

Foi realizada análise de variância, e as diferenças entre as médias foram comparadas pelo teste $\mathrm{F}$, a $5 \%$ de probabilidade, para estudo por meio de regressão.

\section{Resultados e Discussão}

Quanto à produtividade a cada biênio, não houve interação entre os fatores espaçamento na linha e entre as linhas; por isso, estes fatores foram analisados isoladamente. As médias de produtividade observadas para cada biênio estão apresentadas na Tabela 1. Ao considerar-se as médias estimadas em todos os biênios analisados, as parcelas com espaçamento de 2,0 m entre as linhas foram as mais produtivas. Houve variação no decréscimo da produtividade, com o aumento do espaçamento, conforme o biênio em análise.

No primeiro biênio (1994/1995), a equação de regressão mostrou queda de 15,43 sacas beneficiadas de café por hectare para cada unidade de aumento no espaçamento entre as linhas, o que representa, com base nas médias estimadas, redução de cerca de 52\% na produtividade, ao aumentar-se o espaçamento entre as linhas de 2,0 m para 3,5 m. No segundo biênio (1996/1997), com base na regressão obtida, o aumento no espaçamento entre as linhas proporcionou queda mais acentuada em comparação ao primeiro biênio (21,85 sacas por metro); porém, manteve percentual semelhante (52\%) ao observado no primeiro biênio.

No terceiro biênio (1998/1999), a queda na produtividade, em virtude do aumento no espaçamento entre as linhas, foi menos expressiva em comparação ao segundo biênio; no entanto, apesar de reduzida, representou queda de $32 \%$, ao comparar-se as médias estimadas entre o maior e o menor espaçamento. No quarto biênio (2000/2001), a queda na produtividade, em função de maiores espaçamentos entre as linhas, manteve-se semelhante ao terceiro biênio; o aumento de $1,50 \mathrm{~m}$ entre as linhas, relativo à diferença entre o espaçamento de 2,00 e $3,50 \mathrm{~m}$, representou queda de $31 \%$ na produtividade da cultura.

A análise conjunta da produtividade das oito colheitas, relativas ao período de 1994 a 2001, resultou na seguinte equação de regressão, $\mathrm{y}=80,9878$ - 14,5249x $\left(\mathrm{R}^{2}=0,99^{* *}\right)$, na qual se observa que a redução média na produtividade por metro de incremento no espaçamento entre as linhas é de 14,52 sacas beneficiadas por hectare.

No espaçamento entre as plantas na mesma linha, houve tendência de ocorrer maior produtividade, em todos os biênios, no menor espaçamento $(0,50 \mathrm{~m})$. No primeiro biênio, houve intensa redução na produtividade da cultura, cerca de 16 sacas beneficiadas por hectare, ao aumentar-se em $0,50 \mathrm{~m}$ o espaçamento entre as plantas na linha. Com base nas médias estimadas, a queda do menor para o maior espaçamento $(1,00 \mathrm{~m})$ foi de $39 \%$.

No segundo biênio, a queda na produtividade com o aumento no espaçamento entre as plantas foi um 
pouco menor em comparação à do primeiro biênio. $\mathrm{O}$ aumento de $0,50 \mathrm{~m}$ no espaçamento representou redução de cerca de 14 sacas beneficiadas de café por hectare. Ao comparar-se a produtividade estimada do menor e do maior espaçamento, houve queda de $25 \%$, com o aumento de $0,50 \mathrm{~m}$ na distância entre as plantas. No terceiro e no quarto biênio, não houve diferenças significativas entre os espaçamentos em relação à produtividade, e as médias apresentaram valores semelhantes (Tabela 1).

A análise dos resultados revelou que a produtividade tende a ser maior nos espaçamentos mais reduzidos nas quatro primeiras colheitas. Após a quinta ou sexta colheita (terceiro biênio), o menor espaçamento não perdeu produtividade em comparação aos maiores espaçamentos, o que indica que, mesmo com a perda de ramos plagiotrópicos baixeiros, em função do autossobreamento, o desempenho produtivo da cultura, em termos gerais, não foi comprometido. Entretanto, é possível que a produtividade não tenha sido reduzida em consequência de um possível ganho em altura das plantas adensadas.

Paulo et al. (2005) e Toledo \& Barros (1999) observaram queda de produtividade no cultivo adensado com o avançar das colheitas; porém, no presente trabalho, a produtividade manteve-se superior aos espaçamentos mais adensados nos quatro biênios avaliados e sem a realização de poda. Ao analisar-se em conjunto as oito colheitas, a equação de regressão obtida $\left(y=54,044-17,2800 x ; R^{2}=0,90 * *\right)$ indicou que, para cada $0,50 \mathrm{~m}$ de incremento no espaçamento entre as plantas na linha, houve redução na produtividade de cerca de 8,5 sacas de café por hectare. A redução, na média dos quatro biênios, é inferior à ocorrida no primeiro e no segundo biênio, o que comprova que a vantagem do adensamento na linha ocorre nos dois primeiros biênios.

A produção por planta demonstra quantitativamente os efeitos do adensamento por indivíduo, o que pode auxiliar o manejo com podas ou a definição de espaçamentos mais adequados. Quanto à produção de café individual (gramas por planta), não houve diferença significativa entre os espaçamentos entre as linhas no primeiro e no segundo biênio (teste F). Isso indica que a redução de até $2,0 \mathrm{~m}$ no espaçamento entre as linhas não provoca competição entre as plantas antes do segundo biênio, ou seja, não causa redução na produção por planta.

No terceiro biênio, no entanto, houve efeito do espaçamento entre as linhas na produção por planta. Contudo, a equação de regressão obtida apresentou baixo ajuste aos dados, sendo significativa apenas a $8 \%$ de probabilidade. A equação indica que, a partir do terceiro biênio, a tendência é que a produção por planta diminua com o adensamento entre as linhas de cultivo.

No quarto biênio, houve efeito do espaçamento entre as linhas na produção por planta, e a equação, embora tenha apresentado baixo ajuste, demonstrou incremento de $71,17 \mathrm{~g}$ por planta por metro adicionado no espaçamento entre as linhas. $\mathrm{Na}$ análise dos valores absolutos (Tabela 1), há um indicativo de que a redução na produção por planta, no terceiro e no quarto biênio, tenha ocorrido principalmente no espaçamento de 2,0 m, já que os espaçamentos de 2,5,3,0 e 3,5 m apresentaram valores próximos. Provavelmente, esse

Tabela 1. Produtividade de cafeeiros submetidos a quatro espaçamentos entre linhas de plantio e três espaçamentos entre plantas na linha de plantio.

\begin{tabular}{|c|c|c|c|c|c|c|c|c|c|c|c|c|}
\hline \multirow[t]{2}{*}{ Biênio } & \multicolumn{4}{|c|}{ Espaçamento entre linhas $(\mathrm{m})$} & \multirow[t]{2}{*}{ Equação de regressão } & \multirow[t]{2}{*}{$\mathrm{R}^{2}$} & \multicolumn{3}{|c|}{ Espaçamento entre plantas $(\mathrm{m})$} & \multirow[t]{2}{*}{ Equação de regressão } & \multirow[t]{2}{*}{$\mathrm{R}^{2}$} & \multirow{2}{*}{$\begin{array}{l}\mathrm{CV} \\
(\%)\end{array}$} \\
\hline & 2 & 2,5 & 3 & 3,5 & & & 0,5 & 0,75 & 1 & & & \\
\hline & \multicolumn{4}{|c|}{ Produtividade $\left(\mathrm{sc} \mathrm{ha}{ }^{-1}\right)$} & & & \multicolumn{3}{|c|}{ Produtividade $\left(\mathrm{sc} \mathrm{ha}^{-1}\right)$} & & & \\
\hline Primeiro (1994/1995) & 47 & 34 & 26 & 24 & $y=75,6977-15,4329 x$ & $0,92 * *$ & 40 & 34 & 24 & $y=57,4710-32,2850 x$ & $0,97 * *$ & 21,07 \\
\hline Segundo (1996/1997) & 63 & 53 & 39 & 32 & $y=107,3375-21,8513 x$ & $0,98 * *$ & 52 & 49 & 39 & $\hat{y}=67,2813-26,7133 x$ & $0,93 * *$ & 14,07 \\
\hline Terceiro (1998/1999) & 36 & 35 & 30 & 24 & $\hat{y}=54,6924-8,2675 x$ & $0,93 * *$ & 32 & 32 & 30 & ns & & 13,75 \\
\hline \multirow[t]{2}{*}{ Quarto (2000/2001) } & 59 & 57 & 49 & 40 & $\hat{y}=86,2160-12,5451 x$ & $0,94^{* *}$ & 53 & 51 & 49 & ns & & 17,04 \\
\hline & \multicolumn{4}{|c|}{ Produção (g por planta) } & & & \multicolumn{3}{|c|}{ Produção (g por planta) } & & & \\
\hline Primeiro (1994/1995) & 396 & 366 & 342 & 376 & ns & & 309 & 417 & 384 & $\hat{y}=257,5694+150,5000 x$ & $0,45^{*}$ & 22,88 \\
\hline Segundo (1996/1997) & 561 & 583 & 513 & 485 & ns & & 415 & 578 & 613 & $y=238,7361+396,1666 x$ & $0,88^{* *}$ & 15,07 \\
\hline Terceiro (1998/1999) & 332 & 397 & 409 & 378 & $\hat{y}=298,0777+29,5777 x$ & $0,32^{\mathrm{ns}}$ & 266 & 392 & 490 & $\hat{y}=59,6666+426,3333 x$ & $0,98^{*}$ & 14,43 \\
\hline Quarto (2000/2001) & 530 & 638 & 668 & 639 & $\hat{y}=423,5666+71,1777 x$ & $0,57^{*}$ & 414 & 652 & 790 & $\hat{y}=54,5555+753,0000 x$ & $0,97^{*}$ & 14,93 \\
\hline
\end{tabular}

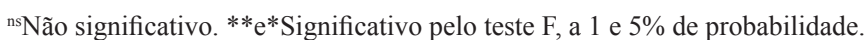


comportamento provocou o baixo ajuste na equação de regressão para o terceiro e o quarto biênio.

No espaçamento entre as plantas na linha, a produção por planta foi afetada em todos os biênios. No primeiro biênio, a equação de regressão apresentou baixo ajuste aos dados, mas indicou aumento na produção por planta com o incremento no espaçamento entre as plantas na linha, o que demonstra que o adensamento entre as plantas na linha afeta a produção por planta desde o primeiro biênio. $\mathrm{O}$ baixo ajuste observado provavelmente foi causado pela diferença mais expressiva em valores absolutos do espaçamento de $0,50 \mathrm{~m}$ em comparação aos de 0,75 e $1,00 \mathrm{~m}$, que apresentaram valores próximos (Tabela 1).

No segundo biênio, a equação de regressão apresentou ajuste satisfatório e indicou incremento de $198 \mathrm{~g}$ de café por planta para um aumento de $0,50 \mathrm{~m}$ no espaçamento entre as plantas. Com base nas médias estimadas, o menor espaçamento, em comparação ao maior, provocou, no segundo biênio produtivo, redução de cerca de $31 \%$ na produção por planta.

No terceiro biênio, a mesma tendência foi observada. Em comparação ao segundo biênio, houve um pequeno incremento no ganho produtivo da planta, com o aumento no espaçamento. A competição entre as plantas no menor espaçamento tende a ficar ainda mais intensa no terceiro biênio; ao comparar-se o maior e o menor espaçamento, há queda na produção por planta de cerca de $44 \%$.

No quarto biênio, o incremento na produção por planta aumenta expressivamente para cada aumento de 0,50 $\mathrm{m}$ no espaçamento entre as plantas na linha, com aumento de cerca de $376 \mathrm{~g}$ por planta. Neste biênio, a competição entre as plantas no menor espaçamento condiciona a baixa produção por planta (redução de cerca de 48\%), que é causada pela limitação de fatores do ambiente, como luz e $\mathrm{CO}_{2}$. Esta fase também é relatada como de "fechamento da lavoura" (Pavan et al., 1994; DaMatta et al., 2007), que se refere à excessiva competição das plantas, tanto na linha de cultivo quanto entre as linhas, em plantios adensados, quando não são realizadas práticas de poda ou arranquio de linhas de cultivo (Pereira et al., 2007).

Ao considerar-se a média de produtividade conjuntamente dos quatro biênios, a equação de regressão $\left(\mathrm{y}=152,8472+431,1666 \mathrm{x} ; \mathrm{R}^{2}=0,93 * *\right)$ representou uma queda média, no período de oito colheitas, de cerca de $215 \mathrm{~g}$ de café por planta com a redução de $0,50 \mathrm{~m}$ no espaçamento entre as plantas na linha de plantio. A redução na produção por planta, causada pelo adensamento entre as plantas na linha, é intensificada ao longo das colheitas com o crescimento individual de cada planta.

Apesar da queda na produção por planta ser expressiva no menor espaçamento, a produtividade manteve-se superior ou semelhante ao maior espaçamento, em todos os biênios. Isso demonstra que o maior número de plantas por unidade de área, no menor espaçamento, é preponderante para a manutenção da produtividade em níveis adequados.

A bienalidade, caracterizada pela alternância anual de altas e baixas produtividades, é comumente atribuída à diminuição das reservas das plantas em anos de safra com altas produtividades, o que faz com que, em virtude do menor crescimento dos ramos plagiotrópicos, a produção no ano seguinte seja baixa, e nem mesmo práticas como a irrigação são capazes de modificar este comportamento (DaMatta et al., 2007; Silva et al., 2008).

No estudo da bienalidade, de 1995 a 2002, avaliado por meio da produtividade, houve efeito do espaçamento entre as linhas de plantio (Tabela 2). A equação da regressão ajustada demonstrou redução na oscilação produtiva entre as colheitas, com o aumento no espaçamento entre as linhas de plantio. Para cada metro de incremento no espaçamento entre linhas, a oscilação entre os anos reduz cerca de 16 sacas de café por hectare. Com base nos dados estimados, a bienalidade do menor para o maior espaçamento,

Tabela 2. Bienalidade de produção de café beneficiado entre 1995 e 2002, em função dos espaçamentos entre linhas e entre plantas na linha de plantio.

\begin{tabular}{|c|c|c|c|c|c|c|c|c|c|c|c|c|}
\hline \multirow[t]{2}{*}{ Variável } & \multicolumn{4}{|c|}{ Espaçamento entre linhas (m) } & \multirow[t]{2}{*}{ Equação de regressão } & \multirow[t]{2}{*}{$\mathrm{R}^{2}$} & \multicolumn{3}{|c|}{ Espaçamento entre plantas $(\mathrm{m})$} & \multirow[t]{2}{*}{ Equação de regressão } & \multirow[t]{2}{*}{$\mathrm{R}^{2}$} & \multirow{2}{*}{$\begin{array}{l}\text { CV } \\
(\%)\end{array}$} \\
\hline & 2 & 2,5 & 3 & 3,5 & & & 0,5 & 0,75 & 1 & & & \\
\hline Produção (g por planta) & 565 & 680 & 620 & 608 & - & - & 428 & 687 & 740 & - & - & 20,02 \\
\hline Produtividade $\left(\mathrm{sc} \mathrm{ha}^{-1}\right)$ & 62,7 & 60,7 & 47,5 & 39,5 & $\hat{y}=98,2555-16,5777 x$ & $0,93 * *$ & 53,1 & 57,8 & 47 & $\hat{y}=150,7500+623,6666 x$ & $0,87 *$ & 17,97 \\
\hline
\end{tabular}

** e * Significativo pelo teste F, a 1 e $5 \%$ de probabilidade. 
de 2,0 para 3,5 m, apresentou redução de cerca de $38 \%$. Ao considerar-se a bienalidade calculada em função da diferença entre os anos de alta e os anos de baixa produção, espera-se que a oscilação entre os espaçamentos mais largos seja menor do que aqueles observados nos espaçamentos mais reduzidos. Prezotti \& Rocha (2004) também verificaram maior efeito da bienalidade no menor espaçamento $(1,00 \times 0,50 \mathrm{~m}) \mathrm{em}$ comparação aos espaçamentos maiores.

Quanto ao efeito do espaçamento entre as plantas, houve diferença na bienalidade de produção; entretanto, não foi possível estabelecer equação de regressão significativa que explique o comportamento observado (Tabela 2). Na produção por planta, não houve efeito do espaçamento entre as linhas de cultivo sobre a bienalidade produtiva de cada planta; e, ao observarse os valores absolutos, não houve tendência comum nos dados obtidos. Assim, é possível inferir que o espaçamento entre as linhas não afeta a bienalidade relativa à produção individual. Entretanto, para o espaçamento entre as plantas na linha, a produção por planta diferiu entre os espaçamentos. A equação de regressão ajustada indicou incremento na bienalidade produtiva de cada planta com o aumento no espaçamento entre as plantas na linha de plantio. $\mathrm{O}$ aumento é de cerca de $312 \mathrm{~g}$ por planta para cada $0,50 \mathrm{~m}$ de aumento no espaçamento. Os valores estimados demonstram, ao comparar-se o menor e o maior espaçamento, um aumento de cerca de $40 \%$ na bienalidade.

A menor produção por planta no menor espaçamento $(0,50 \mathrm{~m})$ entre plantas nas linhas parece condicionar a redução na bienalidade de produção de cada planta. É possível que, em decorrência de um menor esgotamento da planta (menor produção de frutos por planta), ocorra menor oscilação na produção de café individual entre os anos (DaMatta et al., 2007).
Na produção por indivíduo, o adensamento reduziu a bienalidade; porém, na produção por área, o maior adensamento aumentou a oscilação de produtividade entre as colheitas. Dessa forma, mesmo a menor bienalidade de produção por planta, observada no cultivo mais adensado, ao ser multiplicada pelo maior número de plantas por área nesse sistema de cultivo, tende a provocar maior magnitude de oscilação, ao se quantificar a produtividade.

Os espaçamentos entre as linhas de cultivo proporcionarammudanças significativas no crescimento e na arquitetura das plantas, dez anos e seis meses após o plantio (Tabela 3). Como ocorreu nas características produtivas, não houve interação do entre os fatores avaliados, no que se refere ao crescimento.

O decréscimo em altura da planta com o aumento do espaçamento entre as linhas foi demonstrado no modelo de regressão linear obtido. O aumento linear em altura com o adensamento das linhas também foi observado por Martinez et al. (2007), Carvalho et al. (2006a) e Melo et al. (2005), que, em trabalhos semelhantes, concluíram que a redução do espaçamento entre as linhas de cultivo tende a aumentar a competição por luz, o que provoca maior crescimento ou estiolamento do ramo ortotrópico.

Para altura dos ramos plagiotrópicos inferiores, o modelo linear negativo de regressão representou queda na altura da saia com o aumento no espaçamento entre as linhas de cultivo; portanto, as plantas adensadas teriam uma elevação da altura dos primeiros ramos plagiotrópicos, provavelmente em virtude do sombreamento excessivo dos ramos. Segundo Araujo et al. (2008), o café arábica apresenta baixa adaptação ao autossombreamento, o que faz com que os ramos do terço inferior percam suas folhas ao longo do ciclo da planta e cheguem a ponto de secar e morrer.

Tabela 3. Médias das características vegetativas ligadas ao crescimento e à arquitetura das plantas de cafeeiro, em função dos espaçamentos entre as linhas e entre as plantas na linha de plantio, avaliadas em agosto de 2002.

\begin{tabular}{|c|c|c|c|c|c|c|c|c|c|c|c|c|}
\hline \multirow[t]{2}{*}{ Variável } & \multicolumn{4}{|c|}{ Espaçamento entre linhas (m) } & \multirow[t]{2}{*}{ Equação de regressão } & \multirow[t]{2}{*}{$\mathrm{R}^{2}$} & \multicolumn{3}{|c|}{ Espaçamento entre plantas (m) } & \multirow[t]{2}{*}{ Equação de regressão } & \multirow[t]{2}{*}{$\mathrm{R}^{2}$} & \multirow{2}{*}{$\begin{array}{l}\mathrm{CV} \\
(\%)\end{array}$} \\
\hline & 2 & 2,5 & 3 & 3,5 & & & 0,5 & 0,75 & 1 & & & \\
\hline $\operatorname{ALP}(\mathrm{m})$ & 3,09 & 3,04 & 3,04 & 2,88 & $y=3,3367-0,1248 x$ & 0,78 & 3,13 & 3,04 & 2,86 & $y=3,1445-0,535 x$ & $0,94 *$ & 4,4 \\
\hline $\operatorname{ARP}(m)$ & 1,17 & 0,93 & 0,6 & 0,55 & $y=2,0223-0,4382 x$ & $0,94 *$ & 1,02 & 0,73 & 0,68 & $y=1,3334-0,6883 x$ & $0,86^{*}$ & 31,2 \\
\hline $\mathrm{CCO}(\mathrm{m})$ & 1,91 & 2,11 & 2,43 & 3,32 & $y=1,3344+0,3133 x$ & 0,76 & 2,1 & 2,3 & 2,18 & - & - & 12,7 \\
\hline $\mathrm{DCO}(\mathrm{m})$ & 1,56 & 1,69 & 1,78 & 1,76 & $y=-0,0878+1,2252 x-0,1988 x^{2}$ & $1,00^{*}$ & 1,61 & 1,77 & 1,75 & $y=0,7441+2,4816 x-1,4733 x^{2}$ & $1,00^{*}$ & 7,5 \\
\hline $\mathrm{DCA}(\mathrm{mm})$ & 74,22 & 73,49 & 72,34 & 74,84 & - & - & 68,78 & 72,84 & 79,54 & $\mathrm{y}=57,5841+21,5200 x$ & $0,98 *$ & 6,2 \\
\hline
\end{tabular}

(1)ALP, altura de plantas; ARP, altura de ramos plagiotrópicos inferiores; CCO, comprimento de copa; DCO, diâmetro de copa; e DCA, diâmetro de caule. * Significativo pelo teste $\mathrm{F}$, a $5 \%$ de probabilidade. 
A perda de ramos pode ser uma das justificativas para a queda na produtividade nos dois últimos biênios avaliados, que acarretou semelhança produtiva entre o cultivo de maior e menor espaçamento entre as linhas. De acordo com Morais et al. (2008), para que não haja perda no potencial produtivo da planta, durante o período floral, pelo menos $50 \%$ da radiação solar incidente deve ser interceptada pelo dossel do cafeeiro, o que ressalta a necessidade da poda na cultura (Toledo \& Barros, 1999), caso haja fechamento excessivo em determinados espaçamentos.

O comprimento da copa dos cafeeiros, representado pela diferença entre a altura dos cafeeiros e a altura da saia, foi significativamente afetado pelos espaçamentos adotados entre as linhas de plantio. $\mathrm{O}$ modelo linear mostrou relação positiva, em que, para cada $0,50 \mathrm{~m}$ de aumento no espaçamento entre as linhas, obtém-se um aumento de $15 \mathrm{~cm}$ no comprimento da copa dos cafeeiros.

O diâmetro da copa foi influenciado pela distância entre as linhas de plantio e apresentou comportamento quadrático positivo (Tabela 3). Essa ocorrência sugere a existência de diferenças significativas entre os espaçamentos entre as linhas de plantio; no entanto, observa-se a estabilização no diâmetro da copa dos cafeeiros com cerca de 3,0 m entre as linhas de plantio.

O diâmetro de caule dos cafeeiros não foi afetado pela redução de espaçamentos entre as linhas de plantio, possivelmente em consequência da pequena competição por fatores de produção, mesmo nos espaçamentos mais reduzidos $(2,0 \mathrm{~m})$.

Em relação ao espaçamento entre as plantas na linha de plantio, apenas o comprimento de copa não foi influenciado significativamente (Tabela 3 ). A equação linear negativa formada para altura da planta demonstrou que, à medida que se reduz o espaçamento entre as plantas, obtêm-se cafeeiros mais altos, o que permite inferir que há estiolamento das plantas nos espaçamentos menores.

Com base nas equações para altura, o adensamento entre as plantas na linha de plantio foi de maior efeito que o entre as linhas de plantio. Para cada metro de aumento no espaçamento entre as linhas de plantio, obtêm-se plantas $12 \mathrm{~cm}$ menores; já no espaçamento entre as plantas na linha, obtêm-se plantas $53 \mathrm{~cm}$ menores, para cada metro acrescido no espaçamento.
A altura dos ramos plagiotrópicos inferiores dos cafeeiros também foi influenciada pelos espaçamentos entre as plantas na linha de plantio, o que indica redução dos ramos plagiotrópicos baixeiros com adensamento das plantas na linha de cultivo. A perda de plagiotrópicos inferiores do cafeeiro sugere que as operações de poda sejam realizadas em intervalos de tempo compatíveis com o espaçamento da cultura.

À medida que se adensaram as plantas, tanto nas linhas de plantio quanto entre as plantas na linha, maior foi a perda de ramos plagiotrópicos inferiores. $\mathrm{O}$ menor espaçamento entre as linhas $(2 \mathrm{~m})$ provocou um aumento de $112 \%$ na altura de plagiotrópicos inferiores, em comparação ao maior $(3,50 \mathrm{~m})$. $\mathrm{O}$ espaçamento de $0,50 \mathrm{~m}$ entre as plantas causou uma perda de plagiotrópicos inferiores $50 \%$ maior que o de $1,00 \mathrm{~m}$. Portanto, quanto à perda de plagiotrópicos inferiores, o adensamento entre as plantas na linha de plantio afetou mais que o causado pelo adensamento nas linhas de plantio (Tabela 3 ).

Conforme as equações para altura dos ramos baixeiros, a cada aumento de $1 \mathrm{~m}$ entre as linhas de plantio, seriam obtidas alturas de saia $43 \mathrm{~cm}$ menores, enquanto no espaçamento entre as plantas na linha, seriam obtidas plantas com altura de saia $68 \mathrm{~cm}$ menores, para cada metro de aumento.

O diâmetro da copa dos cafeeiros também foi significativamente influenciado pelos espaçamentos entre as plantas na linha de plantio. A equação de regressão revelou efeito quadrático positivo dos espaçamentos adotados sobre o diâmetro da copa. Para o diâmetro do caule, a redução do espaçamento entre as plantas na linha de plantio influenciou negativamente o diâmetro da base do caule. A equação linear negativa permite estimar a redução do diâmetro do caule com o adensamento na linha, em que, para cada $0,25 \mathrm{~m}$ de redução no espaçamento, há uma redução no diâmetro do caule de $5,38 \mathrm{~mm}$, valor semelhante ao alcançado por Paulo et al. (2005).

\section{Conclusões}

1. A redução no espaçamento entre as linhas e entre as plantas na linha de plantio aumentam a produtividade da lavoura cafeeira.

2. Os espaçamentos entre as linhas e entre as plantas na linha de plantio influenciam o crescimento e a arquitetura dos cafeeiros. 


\section{Referências}

ARAUJO, W.L.; DIAS, P.C.; MORAES, G.A.B.K.; CELIN, E.F.; CUNHA, R.L.; BARROS, R.L.; DAMATTA, F.M. Limitations to photosynthesis in coffee leaves from different canopy positions. Plant Physiology and Biochemistry, v.46, p.884-890, 2008.

AUGUSTO, H.S.; MARTINEZ, H.E.P.; SAMPAIO, N.F.; CRUZ, C.D.; PEDROSA, A.W. Produtividade de cultivares de café (Coffea arabica L.) sob espaçamentos adensados. Revista Ceres, v.53, p.539-547, 2006.

BRACCINI, A. de L. e; SCAPIM, C.A.; VIDIGAL FILHO, P.S.; BRACCINI, M. do C.L.; BORGES, S.C.; ALBRECHT, L.P. Características agronômicas e produção de frutos e grãos em resposta ao aumento na densidade populacional do cafeeiro. Acta Scientiarum. Agronomy, v.27, p.269-279, 2005.

BRACCINI, M. do C.L.; BRACCINI, A. de L.; SCAPIM, C.A.; VIDIGAL FILHO, P.S.; ZABINI, A.V. Produção de grãos, concentração e aproveitamento de nutrientes em resposta ao aumento na densidade de plantio do cafeeiro. Acta Scientiarum. Agronomy, v.24, p.1205-1211, 2002.

BRAGANÇA, S.M.; SILVA, E.B.; MARTINS,A.G.; SANTOS,L.P.; LANI, J.A.; VOLPI, P.S. Resposta ao cafeeiro conilon à adubação de NPK em sistema de plantio adensado. Coffee Science, v.4, p.67-75, 2009.

BRUIN, J.L.; PEDERSEN, P. New and old soybean cultivar responses to plant density and intercepted light. Crop Science, v.49, p.2225-2232, 2009.

CARVALHO, C.H.M. de; COLOMBO, A.; SCALCO, M.S.; MORAIS, A.R. de. Evolução do crescimento do cafeeiro (Coffea arabica L.) irrigado e não irrigado em duas densidades de plantio. Ciência e Agrotecnologia, v.30, p.243-250, 2006 a.

CARVALHO, G.R.; MENDES, A.N.G.; BARTHOLO, G.F.; NOGUEIRA, A.M.; AMARAL, M.A. Avaliação de produtividade de progênies de caffeeiro em dois sistemas de plantio. Ciência e Agrotecnologia, v.30, p.838-843, 2006 b.

DAMATTA, F.M.; RONCHI, C.P.; MAESTRI, M.; BARROS, R.S. Ecophysiology of coffee growth and production. Brazilian Journal of Plant Physiology, v.19, p.485-510, 2007.

DEMETRIO, C.S.; FORNASIERI, D.; CAZETTA, J.O.; CAZETTA, D.A. Performance of maize hybrids submitted to different row spacing and population densities. Pesquisa Agropecuária Brasileira, v.43, p.1691-1697, 2008.

GUIMARÃES, P.T.G.; GARCIA, A.W.R.; ALVAREZ, V.H.; PREZOTTI, L.C.; VIANA, A.S.; MIGUEL, A.E.; MALAVOLTA, E.; CORRÊA, J.B.; LOPES, A.S.; NOGUEIRA, F.D.; MONTEIRO, A.V.C.; OLIVEIRA, J.A. de. Cafeeiro. IN: RIBEIRO, A.C.; GUIMARÃES, P.T.G.; ALVAREZ, V.H. (Eds). Recomendações para o uso de corretivos e fertilizantes em Minas Gerais: $5^{\text {a }}$ aproximação. Viçosa, MG:UFV, 1999. P.289-302.

HERNANDEZ-MARTINEZ, G.; MANSON, R.H.; HERNANDEZ, A.C. Quantitative classification of coffee agroecosystems spanning a range of production intensities in central Veracruz, Mexico. Agriculture Ecosystems and Environment, v.134, p.89-98, 2009.
KOUASSI, N.J.; BI, I.A.Z. Effect of sowing density and seedbed type on yield and yield components in Bambara Groundnut (Vigna Subterranea) in woodland savannas of Cote D'ivoire. Experimental Agriculture, v.46, p.99-110, 2010.

LOPES, A.S.; GUIMARÃES, P.T.G. (Coord.). Recomendação para o uso de corretivos e fertilizantes em Minas Gerais: $4^{\mathrm{a}}$ aproximação. Lavras: Comissão de Fertilidade do solo de Minas Gerais, 1989. 176p.

MARTINEZ, H.E.P.; AUGUSTO, H.S.; CRUZ, C.D.; PEDROSA, A.W.; SAMPAIO, N.F. Crescimento vegetativo de cultivares de café (Coffea arabica L.) e sua correlação com a produção em espaçamentos adensados. Acta Scientiarum. Agronomy, v.29, p.481-489, 2007.

MELO, B. de; MARCUZZO, K.V.; TEODORO, R.E.F.; CARVALHO, H. de P.; FERNANDES, D.L. Avaliação de cultivares de cafeeiro com irrigação, em diferentes espaçamentos na linha de plantio. Revista Ceres, v.52, p.245-253, 2005.

MENDES, A.N.G. Avaliação de metodologias empregadas na seleção de progênies do cafeeiro (Coffea arabica L.) no estado de Minas Gerais. 1994. 167p. Tese (Doutorado) - Universidade Federal de Lavras, Lavras.

MENDES, A.N.G.; GUIMARÃES, P.T.G.; MELLES, C.C.A.; BARTHOLO, G.F. Estudo do espaçamento entre e dentro de fileiras para as cultivares Catuaí e Mundo Novo. In: SIMPÓSIO INTERNACIONAL SOBRE CAFÉ ADENSADO, 1994, Londrina. Anais. Londrina: IAPAR, 1994. p.300-301.

MORAIS, H.; MARUR, C.J.; CARAMORI, P.H.; KOGUISHI, M.S.; GOMES, J.C.; RIBEIRO, A.M.D. Floral buds development, flowering, photosynthesis and yield of coffee plants under shading conditions. Pesquisa Agropecuária Brasileira, v.43, p.465-472, 2008.

OLIVEIRA, E.; SILVA, F.M.; SALVADOR, N.; SOUZA, Z.M.; CHALFOUN, S.M.; FIGUEIREDO, C.A.P. Operational costs of mechanized harvest of coffee. Pesquisa Agropecuária Brasileira, v.42, p.827-831, 2007.

PAULO, E.M.; JUNIOR, E.F.; FAZUOLI, L.C. Comportamento de cultivares de cafeeiro em diferentes densidades de plantio. Bragantia, v.64, p.397-409, 2005.

PAVAN, M.A.; CHAVES, J.C.D.; ANDROCIOLI-FILHO, A. Produção de café (Coffea arabica L.) var. Caturra em função da densidade de plantio, adubação e tratamento fitossanitário. Turrialba, v.44, p.227-231, 1994.

PEREIRA, S.P.; GUIMARÃES, R.J.; BARTHOLO, G.F.; GUIMARÃES, P.T.G.; ALVES, J.D. Crescimento vegetativo e produção de cafeeiros (Coffea arabica L.) recepados em duas épocas, conduzidos em espaçamentos crescentes. Ciência e agrotecnologia, v.31, p.643-649, 2007.

PREZOTTI, L.C.; ROCHA, A.C. da. Nutrição do cafeeiro arábica em função da densidade de plantas e da fertilização com NPK. Bragantia, v.63, p.239-251, 2004.

SILVA, C.A.; TEODORO, R.E.F.; MELO, B. Productivity and yield of coffee plant under irrigation levels. Pesquisa Agropecuária Brasileira, v.43, p.387-394, 2008. 
SOUZA, C.A.S.; DIAS, L.A.D.; AGUILAR, M.A.G.; SONEGHETI, S.; OLIVEIRA, J.; COSTA, J.L.A. Cacao yield in different planting densities. Brazilian Archives of Biology and Technology, v.52, p.1313-1320, 2009a.

SOUZA, O.P.; TEODORO, R.E.F.; MELO, B.; TORRES, J.L.R. Fruit quality and productivity of pineapple under different planting densities and irrigation levels. Pesquisa Agropecuária Brasileira, v.44, p.471-477, 2009b.

STEVENS, W.L. Análises estatísticas do ensaio de variedades de café. Bragantia, v.9, p.103-123, 1949.
TOLEDO, S.V.; BARROS, I. de. Influência da densidade de plantio e sistema de podas na produção de café. Pesquisa Agropecuária Brasileira, v.34, p.1379-1384, 1999.

XUE, L.; HAGIHARA, A. Density effects on organs in self-thinning Pinus densiflora Sieb. Et Zucc. stands. Ecological Research, v.23, p.689-695, 2008.

YOUKHANA, A.; IDOL, T. Tree pruning mulch increases soil C and $\mathrm{N}$ in a shaded coffee agroecosystem in Hawaii. Soil Biology and Biochemistry, v.41, p.2527-2534, 2009.

Recebido em 14 de julho de 2010 e aprovado em 27 de dezembro de 2010 